\title{
Durability performance of non-stabilized Compressed Earth Blocks with optimized granular composition
}

\author{
Panagiotou, R. ${ }^{a}$, Kyriakides, M.A. a,b , Illampas, R. ${ }^{a}$, Ioannou, I., ${ }^{a}$, \\ ${ }^{a}$ Department of Civil and Environmental Engineering, University of Cyprus, 75 Kallipoleos Str., P.O. Box 20537, 1678 Nicosia, Cyprus \\ ${ }^{b}$ Department of Engineering, University of Nicosia, 46 Makedonitissas Avenue, P.O.Box 24005, 1700 Nicosia, Cyprus
}

\begin{abstract}
Compressed Earth Blocks (CEBs) have been attracting increasing research interest recently, because of their sustainable nature. However, their poor performance against water-mediated weathering is still considered to be a major drawback for contemporary architecture. The aim of this study is to enhance the durability of non-stabilized CEBs produced in Cyprus by optimizing their granular composition. To that end, two locally sourced soils and a fine crushed aggregate were used to produce several CEBs. Spray erosion, drip and capillary absorption tests were carried out to test the performance of these CEBs against liquid ingress. The results suggest that the addition of sand can significantly improve the durability of non-stabilized CEBs against water action.

Peer-review under the responsibility of the organizing committee of the ICMB21.
\end{abstract}

Keywords: Compressed Earth Block; Durability; Capillary absorption; Spray erosion test; Drip test

\section{Introduction/Background}

Earth is one of the oldest building materials in the world. About $30 \%$ of the world's population still live in earthen structures, mainly located in developing countries [1]. Compressed Earth Blocks (CEBs) comprise a relatively new form of unfired earthen building material; they are produced by mixing soil at a low moisture content, under controlled pressure. Recently, CEBs have been gaining increasing research interest, mainly because of their low embodied energy and excellent recyclability potential [2]. However, the vulnerability of CEBs against water action is still considered to be a major drawback. Chemical stabilizers, such as cement or lime, have been used in order to improve the durability performance of CEBs [3]. However, this practice increases significantly the embodied energy of the end-product [4]. Guettala et al. [5] suggest that an increase in the sand content of the mix design can also improve the performance of CEBs against water attack. In this framework, the present study focuses on the enhancement of the durability of non-stabilized CEBs, by optimizing their granular composition.

\section{Materials and Methods}

Two different locally sourced soils, namely A-soil and T-soil, and a fine crushed calcarenite sand, were used in the mix design of the CEBs hereby presented. The granular composition of the four different mix designs produced was determined according to ASTM D422-63 [6] and is shown in Table 1. "A" and " $\mathrm{T}$ " mix designs refer to the CEBs produced without the addition of sand, whereas "AS" and "TS" mix designs refer to the CEBs produced after adding sand to the initial mix design.

Table 1. Granular composition (\%) of mix designs.

\begin{tabular}{|c|c|c|c|c|}
\hline Mix design & Gravel $(\mathrm{d} \geq 2 \mathrm{~mm})$ & Sand $(0.05 \mathrm{~mm} \leq \mathrm{d}<2 \mathrm{~mm})$ & Silt $(0.002 \mathrm{~mm} \leq \mathrm{d}<0.05 \mathrm{~mm})$ & Clay $(\mathrm{d}<0.002 \mathrm{~mm})$ \\
\hline A & 3 & 26 & 48 & 23 \\
\hline T & - & 29 & 46 & 25 \\
\hline AS & 8 & 48 & 26 & 18 \\
\hline TS & 7 & 55 & 26 & 12 \\
\hline
\end{tabular}

In order to test the performance of the hardened CEBs against liquid action, capillary absorption, spray erosion and drip tests were carried out. Capillary absorption tests were conducted on six cubic specimens with edge $70 \mathrm{~mm}$, using a non-reactive liquid, namely acetone, instead of water. The results were normalized at $20^{\circ} \mathrm{C}$. For the drip tests, six specimens with dimensions $50 \mathrm{~mm}$ x $100 \mathrm{~mm}$ x $100 \mathrm{~mm}$ were used, according to NZS 4298:2020 (Appendix E) [7]. The spray erosion tests were carried out using a customized setup developed according to the guidelines and recommendations found in NZS 4298:2020 (Appendix D) [7]. Six CEBs with dimensions $100 \mathrm{~mm} \times 150 \mathrm{~mm} \times 300 \mathrm{~mm}$ were sprayed with water at a specific rate for $1 \mathrm{~h}$, simulating the effect of long-term rainfall; the maximum depth of erosion was measured after the test on each specimen.

\footnotetext{
*Corresponding author. ioannis@ucy.ac.cy
}

(C) The Author(s). This is an open access article distributed under the terms of the Creative Commons Attribution License (CC BY) 4.0 https:// creativecommons.org/licenses/by/4.0/, which permits unrestricted use, distribution and reproduction in any medium, provided the original author and source are credited. DOI: 10.14293/ICMB210045 


\section{Results and Discussion}

Table 2 summarizes the results of the capillary absorption, spray erosion and drip tests. All specimens tested under capillary absorption demonstrated a linear behaviour with respect to the $t^{1 / 2}$ law, as expected. CEBs made with A-soil had a lower coefficient of absorption, compared to those made with T-soil. After adding sand into the mix design, the coefficients of absorption for both optimised mix designs were significantly reduced. This is likely attributed to the denser structure produced after the addition of sand. The superior performance of "AS" mix design could be the result of better bonding between the sand used and A-soil, as both aforementioned materials were of calcareous nature, as opposed to T-soil, which had a more complex mineralogical composition, consisting of both silicates and carbonates.

In the drip tests, specimens obtained from CEBs made with A-soil experienced an average pit depth of 8.63 mm, whereas those made with T-soil experienced an average pit depth of $8.51 \mathrm{~mm}$. Whilst the differences in the original mix designs were marginal, the two optimised mix designs again demonstrated better behaviour, with "AS" mix design showing superior performance; this is again attributed to the calcareous composition of both A-soil and the calcarenite sand hereby used.

The results of the spray erosion tests on the optimized mix designs were in line with those of the drip tests. CEBs made with Asoil recorded an average rate of erosion of $0.83 \mathrm{~mm} / \mathrm{min}$, whilst those made with $\mathrm{T}$-soil recorded a much higher average rate of erosion $(5.65 \mathrm{~mm} / \mathrm{min})$. With the addition of sand, the rate of erosion was reduced to $0.16 \mathrm{~mm} / \mathrm{min}$ for the "AS" mix design and $0.78 \mathrm{~mm} / \mathrm{min}$ for the "TS" mix design.

Table 2. Average values and coefficient of variation (COV) for the capillary absorption, drip and spray erosion tests.

\begin{tabular}{|c|c|c|c|}
\hline \multirow{2}{*}{ Mix design } & Capillary absorption test & Drip test & Spray erosion test \\
\cline { 2 - 4 } & Coefficient of absorption, $\mathrm{gr} / \mathrm{m}^{2} \mathrm{sec}^{1 / 2}(\mathrm{COV})$ & Pit depth, $\mathrm{mm}(\mathrm{COV})$ & Rate of erosion, $\mathrm{mm} / \mathrm{min}(\mathrm{COV})$ \\
\hline A & $144(14 \%)$ & $8.63(10 \%)$ & $0.83(35 \%)$ \\
\hline T & $182(11 \%)$ & $8.51(9 \%)$ & $5.65(52 \%)$ \\
\hline AS & $83(10 \%)$ & $2.45(35 \%)$ & $0.16(26 \%)$ \\
\hline TS & $128(20 \%)$ & $4.53(32 \%)$ & $0.78(33 \%)$ \\
\hline
\end{tabular}

\section{Conclusions}

The results suggest that granular composition optimization of CEBs through the addition of sand can indeed improve the durability performance of the hardened end-products. All the tests hereby performed have shown considerable improvement in the watermediated behaviour of the hardened CEBs, following the addition of sand to the original mix designs. This confirms that sand may be used as a natural stabilizer to enhance the durability performance of CEBs, without negatively affecting their sustainable nature, as would have been the case with chemical stabilizers. The mineralogical composition of the sand additive used is also important, as it may affect the behavior of the primary raw material, i.e. soil.

\section{Acknowledgements}

The authors would like to acknowledge funding by the University of Cyprus, and the European Regional Development Fund and the Republic of Cyprus, through the Cyprus Research and Innovation Foundation (Project ENTERPRISES/0618/0007). They would also like to thank Mr. M. Tapakoudis from Gigantas Antaios Touvlopiio Ltd for his help with the production of CEBs.

\section{References}

[1] Houben H. and Guillaud H. 1994. Earth construction: A comprehensive guide, p. 6-13.

[2] Barrera M.M. B. Sandoval M. J. Iglesias S. G. (2020). Assessment of the effect of natural hydraulic lime on the stabilisation of compressed earth blocks, Construction and Building Materials, 260, 119877.

[3] Walker P. J. (2004). Strength and erosion characteristics of earth blocks and earth block masonry. Journal of Materials in Civil Engineering, 16(5), 497-506.

[4] Malkanthi S. N. Balthazaar N. Perera A. A. D. A. J. (2020). Lime stabilization for compressed stabilized earth blocks with reduced clay and silt. Case Studies in Construction Materials, 12, e00326.

[5] Guettala A. Mezghiche B. Chebili R. and Houari H. (2002) Durability of lime stabilised earth blocks. Challenges of Concrete Construction Sustainable Concrete Construction, 5, 645-654.

[6] ASTM D422-63, Standard test method for particle-size analysis of soils, ASTM International, West Conshohocken, PA, 2002

[7] NZS 4298:2020 Materials and workmanship for earth buildings, New Zealand Standards, New Zealand, 2020. 